\title{
Immunocytological and Biochemical Localization and Biological Activity of the Newly Sequenced Cerebral Peptide 2 in Aplysia
}

\author{
Gregg A. Phares and Philip E. Lloyd \\ Committee on Neurobiology and Department of Pharmacological and Physiological Sciences, University of Chicago, \\ Chicago, Illinois 60637
}

Cerebral peptide 2 (CP2), a 41 amino acid neuropeptide, was identified because it was transported from the cerebral ganglia of Aplysia to other central ganglia. Immunocytology indicates that CP2 is distributed widely in the CNS and peripheral tissues of Aplysia. Most CP2-immunoreactive neurons were found in the cerebral ganglia and extensively overlap with the distribution of cerebral peptide 1 (CP1). HPLC analyses confirm that individual cerebral neurons synthesize both CP1 and CP2. In other ganglia, CP1 and CP2 are localized predominantly to different neurons. CP2-immunoreactive fibers and varicosities are present in the neuropil of all ganglia but were found surrounding cell bodies and axon hillocks most often in the buccal and abdominal ganglia. Thus, the effects of CP2 on neurons in these ganglia were determined using intracellular recording. In the buccal ganglia, CP2 evokes rhythmic activity in many motor neurons that seems similar to that observed during ingestion; however, only one identified neuron was found to be depolarized directly. By contrast, in the abdominal ganglion, many neurons are depolarized directly by CP2. A number of these have been shown to be part of the circuit that regulates respiratory pumping. Injection of CP2 into freely behaving Aplysia increases the rate of respiratory pumping and causes other changes in behavior. CP2 is stable in hemolymph, which raises the possibility that it may act as a hormone. Thus, CP2 is a bioactive neuropeptide that is present in many neurons and likely functions as a transmitter or a hormone.

Key words: neuropeptide; immunoreactivity; cerebral ganglia; identified neurons; axonal transport; peptide biosynthesis
We have been studying peptidergic synaptic transmission in Aplysia and have recently begun to characterize previously unidentified peptides that may be important in interganglionic communication. The CNS of Aplysia is composed of five major ganglia linked together by connective nerves. Peptide transmitters that are used for communication between ganglia would be expected to be synthesized in neuronal cell bodies in one ganglion and transported by fast axonal transport via axons in the connective nerves to release sites in target ganglia. Neuropeptides transported from the cerebral ganglia to other ganglia may be particularly important in behavioral regulation, because the cerebral ganglia receive input from many sensory structures and seem to be involved in the higher-order control of many behaviors (Kandel, 1979). Although neurons in the cerebral ganglia that are involved in the initiation or modulation of behavior have been identified, little is known about the neuropeptides they may use as transmitters.

In a series of experiments that studied fast axonal transport of $\left[{ }^{35} \mathrm{~S}\right]$ methionine-labeled peptides between central ganglia, several previously uncharacterized peptides were found to be synthesized in the cerebral ganglia and transported primarily to the abdominal and pedal ganglia (Lloyd, 1989). Two of these peptides, termed cerebral peptide 1 (CP1) and CP2, were targeted for purification (Phares and Lloyd, 1996; Phares et al., 1996). With the use of sequential modes of HPLC, radiolabeled peptide probes gener-

Received Aug. 26, 1996; revised Sept. 23, 1996; accepted Sept. 26, 1996.

This work was supported by National Institutes of Health Training Grant T32GM-07839 to G.A.P., National Science Foundation Grant IBN-9418815, and a grant from the Brain Research Foundation to P.E.L. We thank Lyle Fox for critically reading this manuscript.

Correspondence should be addressed to Philip E. Lloyd, Committee on Neurobiology, University of Chicago, 947 East 58th Street, Chicago, IL 60637.

Copyright (C) 1996 Society for Neuroscience $0270-6474 / 96 / 167841-12 \$ 05.00 / 0$ ated by transport experiments were used to monitor the purifications from extracts of cerebral ganglia. Both peptides were purified and sequenced: CP1 is a 13 amino acid peptide with no post-translational modifications; CP2 is a 41 amino acid peptide with an amidated C terminal (Phares and Lloyd, 1996; Phares et al., 1996).

The immunocytological distribution of CP1 in the CNS of Aplysia has been described (Phares and Lloyd, 1996). Neuronal cell bodies containing CP1-like immunoreactivity (CP1-lir) were found in each of the major ganglia, but the majority was located in the cerebral ganglia. In the present study, we report the distribution of CP2-lir in the CNS and certain peripheral structures. Neurons containing CP2-lir were found throughout the CNS but were most numerous in the cerebral ganglia, with a distribution similar to neurons positive for CP1-lir. Immunocytological and biochemical results presented here suggest that $\mathrm{CP} 1$ and $\mathrm{CP} 2$ are often but not always colocalized in neurons. Fibers containing $\mathrm{CP} 1$-lir and CP2-lir were found throughout the CNS and in a number of peripheral tissues. We also found that a number of identified neurons in the buccal and abdominal ganglia responded electrophysiologically to $\mathrm{CP} 2$, and that injection of $\mathrm{CP} 2$ into an animal reliably elicits a number of behavioral responses. Thus, we have identified in $\mathrm{CP} 2$ a new neuropeptide that seems to be involved in synaptic transmission between neurons in the cerebral ganglia and neurons in the remainder of the CNS.

\section{MATERIALS AND METHODS}

\section{Animals}

Aplysia californica (1-250 gm) were obtained from Marinus (Long Beach, $\mathrm{CA}$ ) and maintained in circulating artificial seawater (ASW) tanks at $15^{\circ} \mathrm{C}$. Before dissection, the animals were immobilized by an injection of isotonic $\mathrm{MgCl}_{2}$ equal to $50 \%$ of their body weight. 


\section{Antisera}

The amino acid sequence of $\mathrm{CP} 1, \mathrm{NH}_{2}$-FSGLMSEGSSLEA-COOH, and the anti-CP1 serum 1693 used in this study have been described (Phares and Lloyd, 1996). The amino acid sequence of CP2, $\mathrm{nh}_{2}$-FDFGFAGLDTYDAIHRALEQPARGTSNSGSGYNMLMKMQRH-amide, has also been reported (Phares et al., 1996). Rabbit antisera against CP2 were prepared by a commercial source (ImmunoDynamics, La Jolla, CA). A synthetic peptide corresponding to the first 17 residues from the amino terminal of CP2, with a cysteine substituted for the amino terminal phenylalanine, Cys ${ }^{1}$-CP2[2-17], was conjugated to porcine thyroglobulin via the amino terminal cysteine residue and injected into two rabbits for immunization and subsequent boosts at 3 week intervals. After 10 weeks, the antisera, designated 1446 and 1447, were tested on an ELISA using the synthetic peptide conjugated to bovine serum albumin as the antigen. When used for immunocytology, antiserum 1446 and 1447 produced similar staining, but 1447 was used routinely because of its lower background staining.

\section{Immunoblot analysis of CP1 and CP2 antisera}

The central ganglia from two animals $(\sim 100 \mathrm{gm})$ were extracted in $20 \mathrm{mM}$ trifluoroacetic acid (TFA), $28 \mathrm{~mm}$ 2-mercaptoethanol (2-ME) at $100^{\circ} \mathrm{C}$ for $10 \mathrm{~min}$. Pooled extracts of the cerebral ganglia or of the remaining central ganglia minus the cerebral ganglia were run on HPLC (as described below for single neurons). The resulting fractions were dried and brought to a volume of 10 or $30 \mu \mathrm{l}$ with $20 \mathrm{~mm}$ TFA, $70 \% \mathrm{CH}_{3} \mathrm{CN}$ (the volume that was used depended on the size of the fraction). Volumes of 1-3 $\mu \mathrm{l}$ were blotted on Immobilon-P membrane (polyvinylidene difluoride, $0.45 \mu \mathrm{m}$ pore size; Millipore, Bedford, MA) coated with $5 \%$ normal goat serum (NGS; Life Technologies, Gaithersburg, MD) in PBS. Membranes were also blotted with synthetic CP1 or Cys ${ }^{1}$-CP2[2-17] (0.01-100 pmol). Membranes were fixed for $4 \mathrm{hr}$ in $4 \%$ paraformaldehyde vapor at $40^{\circ} \mathrm{C}$ and then air-dried. Membranes were wetted with methanol, washed in several changes of water, and then washed in PBS. Nonspecific binding of antisera was blocked with 5\% NGS and $0.2 \%$ Tween 20 in PBS $(0.14 \mathrm{M} \mathrm{NaCl}, 0.01 \mathrm{~m}$ phosphate, $\mathrm{pH} 7.4)$. Membranes were incubated with antisera against either CP1 (1693 diluted 1:10,000) or CP2 (1447 diluted 1:20,000) for $12 \mathrm{hr}$, rinsed in several changes of 5\% NGS, $0.2 \%$ Tween 20, and incubated in a 1:200 dilution of goat anti-rabbit IgG (GAR)-biotin (Vector, Burlingame, CA) in 5\% NGS, $0.2 \%$ Tween 20 for $2 \mathrm{hr}$, and then rinsed in several changes of 5\% NGS, $0.2 \%$ Tween 20 , followed by several changes in $0.2 \%$ Tween 20 in PBS. Membranes were incubated in a 1:500 dilution of avidin-biotin complex conjugated to horseradish peroxidase (ABC-HRP; Vectastain Elite kit, Vector) for 1.5 hr, washed in several changes of $0.2 \%$ Tween 20 in PBS and then PBS alone, and developed in $0.025 \%$ diaminobenzidine (DAB) $/ 0.0125 \%$ $\mathrm{H}_{2} \mathrm{O}_{2}$.

\section{Tissue preparation and staining}

Whole mounts. Immunocytology of whole mounts was carried out using the methods of Longley and Longley (1986), as modified by Pearson and Lloyd (1989). Ganglia and peripheral tissues were dissected from immobilized animals and pinned out in a dish with a Sylgard (Corning, Corning, $\mathrm{NY})$ base in a low $\mathrm{Ca}^{2+}(0.5 \mathrm{~mm} ; 0.05 \times$ normal $)$, high $\mathrm{Mg}^{2+}(110 \mathrm{~mm} ; 2 \times$ normal) ASW (termed low Ca ASW). Tissue was fixed in $4 \%$ paraformaldehyde, $30 \%$ sucrose in $0.1 \mathrm{~m}$ phosphate buffer (PB), $\mathrm{pH} 7.4$, for $4 \mathrm{hr}$ at room temperature or overnight at $4{ }^{\circ} \mathrm{C}$. After fixation, the tissue was washed in $\mathrm{PB}$ and then in $\mathrm{PB}$ containing $1 \%$ Triton $\mathrm{X}-100,0.1 \%$ sodium azide for 12-24 hr. After this wash, ganglia were desheathed manually. Nonspecific binding of antibodies was blocked by incubating the tissue in a blocking solution of PBS with $1 \%$ Triton X-100, $0.1 \%$ sodium azide, and $5 \%$ NGS overnight. Primary and secondary antisera were diluted in this blocking solution. Anti-CP2 serum 1447 was diluted 1:10,000 for use with the ABC-HRP or 1:1000 for use with GAR IgG conjugated to a fluorophore. Fluorescent secondary antisera GAR-aminomethylcoumarin acetate (GAR-AMCA; Jackson Labs, Bar Harbor, ME) or GAR-fluoroscein isothiocyanate (GAR-FITC; Jackson Labs) were used at a dilution of $1: 100$. Tissue was mounted in $1 \% n$-propyl gallate in a $1: 6 \mathrm{PBS} /$ glycerol solution, $\mathrm{pH} 8.5$. When the secondary antisera were GAR-conjugated to HRP (GAR-HRP, 1:100 dilution; Jackson Labs) or GAR-biotin (1:400 dilution; Vector) followed by incubation with ABC-HRP (1:500 dilution; Vector), the tissue was incubated in $0.025 \%$ DAB (Sigma, St. Louis, MO), $0.0125 \% \mathrm{H}_{2} \mathrm{O}_{2}$, after which it was rinsed in PBS, dehydrated in a series of increasing concentrations of ethanol and then in 50\% ethanol/ $50 \%$ xylenes, and finally in $100 \%$ xylenes, and mounted in DPX (Fluka, Buchs, Switzerland).
Sections. The initial handling of the tissue was the same as for whole mounts. Before the wash in Triton X-100, the tissue was embedded in $12 \%$ gelatin in $20 \mathrm{~mm}$ PBS, with or without $15 \%$ sucrose. After the gelatin had set, tissue blocks were fixed overnight at $4^{\circ} \mathrm{C}$ in $4 \%$ paraformaldehyde, $30 \%$ sucrose. Frozen sections $(20-25 \mu \mathrm{M})$ were cut and transferred to PBS in nylon mesh-bottomed wells for staining. The solutions used for sections were the same as those for whole mounts except that $0.5 \%$ Triton $\mathrm{X}-100$ was used. Primary and secondary antisera were diluted in blocking solution. Sections were mounted on gelatin-coated glass slides using the the appropriate media as described for whole mounts.

Specificity of staining was tested by the immunoblot procedure described above and by preabsorption of diluted primary antisera with 100 $\mu \mathrm{M}$ synthetic peptide (CP1 for 1693 or $\mathrm{Cys}^{1}-\mathrm{CP} 2$ [2-16] for 1447) for $16 \mathrm{hr}$ at $4^{\circ} \mathrm{C}$, centrifugation at low speed, and use of the upper portion of the supernatant for immunocytology. No staining was observed for either of the peptide preabsorbed antisera. Neither preimmune antisera produced staining.

\section{Comparison of CP1-lir and CP2-lir}

Whole mounts of ganglia were processed using a technique developed for double-labeling for two monoclonal primary antibodies (Wessel and McClay, 1986) modified for polyclonal rabbit antisera and Aplysia tissue. Briefly, the first primary antiserum was applied, and after it was washed, a high concentration (1:25) of goat anti-rabbit Fab fragment conjugated to either FITC or lissamine rhodamine sulfonyl chloride (LRSC; Jackson Labs) was used as the secondary antiserum. After this tissue was washed to remove excess secondary antiserum, the second primary antiserum was applied, followed by a wash, and then incubation with goat anti-rabbit $\operatorname{IgG}(1: 100)$ conjugated to either AMCA or FITC. Controls for this procedure were preabsorption of the first or second primary antiserum with the appropriate synthetic peptide. This procedure worked well for whole mounts (see Fig. 4), but despite many procedural modifications, we were unable to develop conditions that produced acceptable doublestaining in sections. Thus, for sections of ganglia or peripheral tissues, alternate sections were incubated with anti-CP1 or anti-CP2 sera followed by GAR-HRP secondary antisera. For peripheral tissues, the entire buccal mass, gill, kidney, heart, genital tract, penis complex, foot, and body wall from several small animals (1-5 gm) were sectioned. Portions of these tissues from larger animals $(50-250 \mathrm{gm})$ were also sectioned.

\section{Interganglionic transport}

Transport experiments were carried out as described previously (Lloyd, 1989). Briefly, cerebral, pedal-pleural, and abdominal ganglia were removed, with their connective nerves intact, and transferred to a transport chamber. The cerebral ganglia were isolated from the other ganglia by running the intact cerebral connectives through a polypropylene and petroleum jelly diffusion barrier. The cerebral ganglia were incubated for $24 \mathrm{hr}$ with $0.5 \mathrm{mCi}\left[{ }^{35} \mathrm{~S}\right]$ methionine $(>1000 \mathrm{Ci} / \mathrm{mmol}$; Amersham, Arlington Heights, IL) in $0.5 \mathrm{ml}$ of $50 \%$ ASW $(460 \mathrm{~mm} \mathrm{NaCl}, 10 \mathrm{~mm} \mathrm{KCl}, 11 \mathrm{~mm}$ $\mathrm{CaCl}_{2}, 55 \mathrm{~mm} \mathrm{MgCl}_{2}, 5 \mathrm{~mm} \mathrm{NaHCO}, \mathrm{pH} 7.8$ ), $50 \%$ hemolymph, $0.01 \%$ glucose, $25 \mathrm{U} / \mathrm{ml}$ penicillin, $25 \mu \mathrm{g} / \mathrm{ml}$ streptomycin, and $0.01 \%$ 2-ME. The remaining ganglia were incubated in $150 \mathrm{ml}$ of ASW with $10 \% \mathrm{~L} 15$ culture medium (Sigma) modified to have the same salt composition as ASW, $0.01 \%$ glucose, $25 \mathrm{U} / \mathrm{ml}$ penicillin, $25 \mu \mathrm{g} / \mathrm{ml}$ streptomycin, and $0.01 \%$ 2-ME. The labeling period was followed by a $24 \mathrm{hr}$ chase with 1 $\mathrm{mm}$ unlabeled methionine in the ASW, L15 medium. The pleuralabdominal connectives, the abdominal ganglion, and the major nerves that leave the abdominal ganglion were then extracted separately in 0.5 $\mathrm{ml}$ of $20 \mathrm{~mm}$ TFA and $28 \mathrm{~mm} 2-\mathrm{ME}$, heated to $100^{\circ} \mathrm{C}$ for $10 \mathrm{~min}$, homogenized, and centrifuged at $10,000 \times g$ for $10 \mathrm{~min}$. The supernatant was filtered $(0.45 \mu \mathrm{m}, \mathrm{LC} 13$, Gelman, or $0.2 \mu \mathrm{m}$, Microspin) and run on HPLC (as described below for single cells).

\section{Synthesis of CP1 and CP2 by single neurons}

Putative CP1- and CP2-synthesizing neurons were identified by relative size and location in living ganglia based on observations of immunocytological staining of whole mounts. Neurons were electrophoretically injected with a vital dye (1\% fast green; Sigma) via an intracellular electrode (Church and Lloyd, 1991). Newly synthesized peptides were labeled by incubating ganglia in a $0.5 \mathrm{ml}$ solution of $50 \%$ Aplysia hemolymph, $50 \%$ ASW containing $1 \mathrm{~mm}$ colchicine, $25 \mathrm{U} / \mathrm{ml}$ penicillin, $25 \mu \mathrm{g} / \mathrm{ml}$ streptomycin, $0.1 \%$ 2-ME, and $0.5 \mathrm{mCi}\left[{ }^{35} \mathrm{~S}\right]$ methionine (Amersham) for $20 \mathrm{hr}$ at room temperature $\left(\sim 20^{\circ} \mathrm{C}\right)$. The labeling period was followed by a $4 \mathrm{hr}$ chase with $1 \mathrm{~mm}$ unlabeled methionine in ASW. Individual 
neuronal cell bodies were dissected using the freeze substitution technique (Ono and McCaman, 1980) and were transferred to polypropylene microtubes containing $50 \mu \mathrm{l}$ of $20 \mathrm{~mm}$ TFA, $28 \mathrm{~mm} 2-\mathrm{ME}$, and $2 \mathrm{nmol}$ each of synthetic buccalin A (BuA; American Peptide Co.), CP1 (BioSynthesis), CP2 (AnaSpec), FMRFamide (Bachem, Torrance, CA), myomodulin A (MmA; Peninsula, Belmont, CA), and pedal peptide (Applied Biosystems). Extracts were heated at $100^{\circ} \mathrm{C}$ for $10 \mathrm{~min}$, cooled, $50 \mu \mathrm{l}$ of $\mathrm{CH}_{3} \mathrm{CN}$ was added, and the sample was filtered $(0.45 \mu \mathrm{m}$; Microspin). The filters were rinsed with $50 \mu \mathrm{l}$ of $50 \% \mathrm{CH}_{3} \mathrm{CN}$ in $10 \mathrm{~mm}$ heptafluorobutyric acid (HFBA), and the volume was brought to $500 \mu \mathrm{l}$ with $10 \mathrm{~mm}$ HFBA. Samples were analyzed by HPLC using an Aquapore RP-300 C8 column $(4.6 \times 220 \mathrm{~mm}$; Pierce, Rockford, IL). The initial separation used a linear gradient from 15 to $50 \% \mathrm{CH}_{3} \mathrm{CN}$ in $23.3 \mathrm{~min}$ (counterion: $10 \mathrm{~mm}$ HFBA). Fractions were collected, and aliquots were liquid-scintillation counted. In some cases, aliquots of fractions were pooled, dried, and analyzed using a second gradient from 5 to $45 \% \mathrm{CH}_{3} \mathrm{CN}$ in $20 \mathrm{~min}$ (counterion: $10 \mathrm{~mm}$ TFA).

\section{Electrophysiology}

Ganglia were manually desheathed. Neurons were identified on the basis of published characteristics, including relative size, location, pigmentation, and synaptic connections. Identified neurons were impaled with single microelectrodes (3-8 M 2 ) containing $3 \mathrm{M}$ potassium acetate and $0.1 \%$ fast green. Action potential durations were measured at the halfmaximal amplitude of the first action potential after a long period of hyperpolarization $(\sim 60 \mathrm{sec})$ to reduce the influence of previous firing frequency. Recordings were carried out in normal ASW (nASW), low Ca ASW (see Tissue preparation and staining), or high $\mathrm{Ca}^{2+}(33 \mathrm{~mm} ; 3 \times$ normal), high $\mathrm{Mg}^{2+}\left(165 \mathrm{mM} \mathrm{MgCl}_{2} ; 3 \times\right.$ normal) (termed high $\mathrm{Ca}$, high $\mathrm{Mg}$ ASW). A minimum superfusion period of $1 \mathrm{hr}$ was used when changing to different ASWs. Synthetic peptides were applied in a $500 \mu \mathrm{l}$ bolus via an injection loop into a $500 \mu \mathrm{l}$ bath. A flow rate of $\sim 1 \mathrm{ml} / \mathrm{min}$ was used.

\section{Stability of CP2 in hemolymph}

CP2 was incubated in hemolymph taken from a cold-anesthetized animal (15 min at $4^{\circ} \mathrm{C}$ ) as described previously (Hall and Lloyd, 1990). Briefly, radiolabeled $\mathrm{CP} 2$ was purified from pooled $\mathrm{H}, \mathrm{B}$, and $\mathrm{G}$ cluster neurons by HPLC, combined with synthetic CP2 (final total concentration $\sim 1$ $\mu \mathrm{M})$, and incubated in either previously boiled hemolymph or fresh hemolymph for $20 \mathrm{~min}$ at $22^{\circ} \mathrm{C}$. Aliquots of the samples were removed periodically and diluted into $500 \mu \mathrm{l} 20 \mathrm{~mm}$ TFA, $28 \mathrm{~mm}$ 2-ME containing excess unlabeled synthetic CP2 $(5 \mathrm{nmol})$. This sample was centrifugefiltered and analyzed by HPLC using the TFA gradient described above.

\section{Injection of CP2 into freely behaving animal}

Each animal was weighed, isolated in a floating plastic cage within the aquarium, and observed for $15 \mathrm{~min}$ before injection. Overall behavior and the number of respiratory pumps (RPs) were noted. Animals were then injected with 100-300 nmol synthetic CP2 (depending on the size of the animal) in 200-500 $\mu \mathrm{lnASW}$ and observed for $30 \mathrm{~min}$. Control animals were handled in the same manner but were injected with only nASW.

\section{RESULTS}

\section{CP2-like immunoreactivity in the CNS}

The specificity of the antisera were determined using immunoblots of HPLC fractions from extracts of cerebral ganglia or the total CNS minus the cerebral ganglia. Aliquots of HPLC fractions were blotted onto membranes and incubated with either the anti-CP1 serum (1693) or the anti-CP2 serum (1447). The antiCP1 serum detected immunoreactivity only in the fractions in which synthetic CP1 eluted in a parallel run, and the anti-CP2 serum detected immunoreactivity only in the fractions in which synthetic $\mathrm{CP} 2$ eluted in a parallel run. Immunoblots are only semiquantitative, but comparisons of the intensities of immunoreactivity from tissues with those from synthetic peptides indicated that the paired cerebral ganglia contained 1-10 pmol of CP1 or $\mathrm{CP} 2$, which agree with values estimated from the purifications: $\sim 6$ pmol $\mathrm{CP} 1$ and $\sim 4$ pmol $\mathrm{CP} 2$ per paired cerebral ganglia (Phares and Lloyd, 1996; Phares et al., 1996). From the immuno- blots we estimated that the remainder of the CNS contains 1-10 pmol CP1 and 0.1-1 pmol CP2. These relative values correlate roughly with the nature and intensity of immunocytological staining that we observed (see below).

$\mathrm{CP} 2$-lir was found in axons and varicosities in the neuropil of all the major ganglia and in axons in every connective and peripheral nerve except the optic and buccal nerves. Positive cell bodies were localized predominantly to the cerebral ganglia. Neurons of cerebral ganglia have been divided into clusters designated A through M (Jahan-Parwar and Fredman, 1976; Ono and McCaman, 1980). On the dorsal surfaces, cell bodies containing CP2-lir were located in the B, C, D, E, G, and H clusters (Figs. 1 and 5). Another cluster of small teardrop-shaped neurons located at the lateral margin of the cerebral-pleural connective (caudal to the D cluster and ventral to the A cluster) also contained CP2-lir. On the ventral surface of the cerebral ganglia (Figs. 1 and 2), neurons containing CP2-lir were found in the $\mathrm{B}, \mathrm{G}$, and $\mathrm{H}$ clusters (neurons in many clusters are located on both ventral and dorsal sides of each ganglion), as well as in a medial cluster of cells immediately adjacent to and on both sides of the commissure, which we have designated the $\mathrm{N}$ cluster, extending the established nomenclature for cerebral neuronal clusters (Jahan-Parwar and Fredman, 1976). CP2-lir was also observed in several cell bodies in the anterior region of each pleural ganglion (Fig. 5). In the buccal ganglion, immunoreactive fibers were found predominantly in the lateral region of the neuropil and surrounding the cell bodies and initial segments and cell bodies of several small neurons (Fig. $3 A$ ). In addition, CP2-lir was observed in a cluster of very small neurons on the caudal surface of each buccal ganglion lateral to where the esophageal nerve exits the ganglion (not shown). Three clusters of neurons in the abdominal ganglion were also immunoreactive for CP2. One cluster was located in the left hemiganglion at the lateral margin of the dorsal surface. Another cluster was in the right lower quadrant between identified neurons R2 and R15 (Fig. 3B). Most of these cells were below the surface layer of neurons, just above the neuropil. The third cluster is located at the lateral margin of the right upper quadrant. CP2-lir was also observed in varicose axons surrounding the bag cells (Fig. $3 C$ ). In the pedal ganglia, no cell bodies contained CP2-lir, but many immunoreactive fibers and varicosities were found in the neuropil and peripheral nerves.

\section{Colocalization of CP1-lir and CP2-lir in the CNS}

The localization of CP2-lir in the cerebral ganglia was similar to that observed previously for CP1-lir (Phares and Lloyd, 1996). Figure 4 shows the ventral surface of cerebral ganglia that were double-stained for CP1-lir and CP2-lir. Many neurons were immunoreactive for both peptides, including those of the $\mathrm{B}, \mathrm{G}, \mathrm{H}$, and $\mathrm{N}$ clusters; however, several neurons contained only CP1-lir or CP2-lir but not both. For example, neurons containing only CP1-lir were found in the bilaterally symmetrical rostral E and M clusters of the cerebral ganglion. On the dorsal surface, many of the smaller neurons seemed to contain only CP1-lir or CP2-lir (Fig. 5). CP2-lir, but not CP1-lir, was observed in an asymmetric cluster of small neurons in the right pleural ganglion (Fig. 4). These neurons were located between the pleural sensory neurons and the posterior cluster on the medial surface of the ganglion (Kehoe, 1972). Neurons in the anterior cluster contained either CP1-lir or CP2-lir or both (Fig. 5). In other ganglia, CP1-lir and $\mathrm{CP} 2$-lir were found in different populations. For example, the bilateral clusters of pedal neurons that were immunoreactive for CP1 (Phares and Lloyd, 1996) did not contain CP2-lir. 

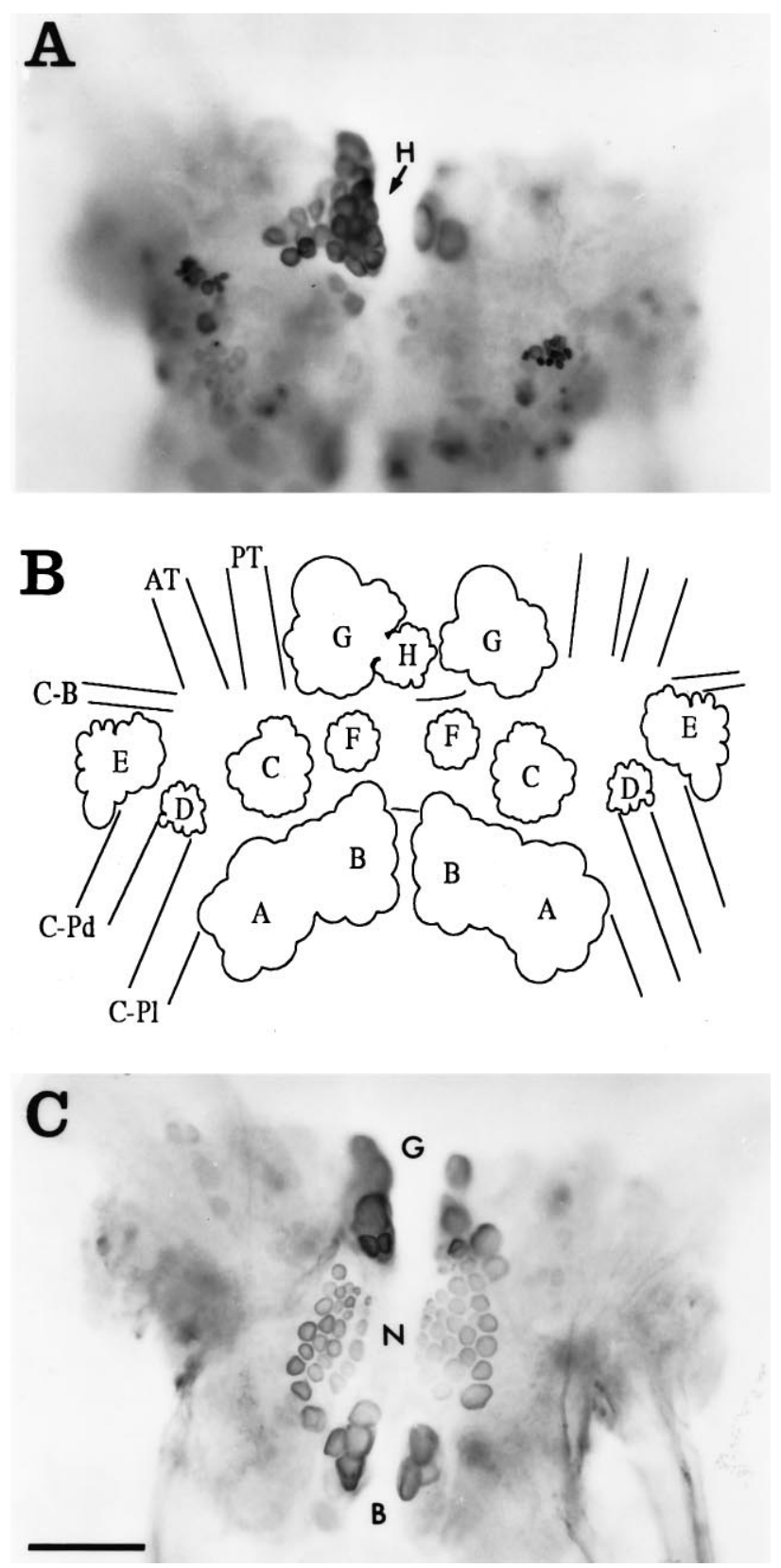

Figure 1. Whole mounts showing the locations of neurons containing CP2-lir in the cerebral ganglia visualized using GAR-biotin and $\mathrm{ABC}-\mathrm{HRP}$ as viewed from the ventral surface. $A$, Dorsal surface. The location of the $H$ cluster is indicated (arrow). $B$, Diagram of the dorsal surface illustrating the positions of the major neuronal clusters. $C$, Ventral surface. The labels for $G, N$, and $B$ clusters are positioned between these bilateral clusters. Immunoreactive neuronal cell bodies are located in a number of neuronal clusters on both sides of the ganglia (see text). Photomicrographs and diagram are as viewed from the ventral side, so right and left ganglia appear reversed for $A$ and $B$. Neuronal clusters are designated as in Jahan-Parwar and Fredman (1976), except the $N$ cluster (see text). $A T$, Anterior tentacular nerve; $C-B$, cerebralbuccal connective; $C$ - $P d$, cerebral-pedal connective; $C$ - $P l$, cerebral-pleural connective; $P T$, posterior tentacular nerve. Scale bar (shown in $C$ ): $200 \mu \mathrm{m}$ (applies to $A-C$ ).

In the periphery, CP1-lir and CP2-lir were found in fibers in the gill, foot, body wall, and genital tract, whereas only fibers containing CP2-lir were observed in the penis. Neither CP1-lir nor CP2-lir was observed in the heart, kidney, or buccal mass. Because many of the peripheral tissues innervated by the abdominal gan-

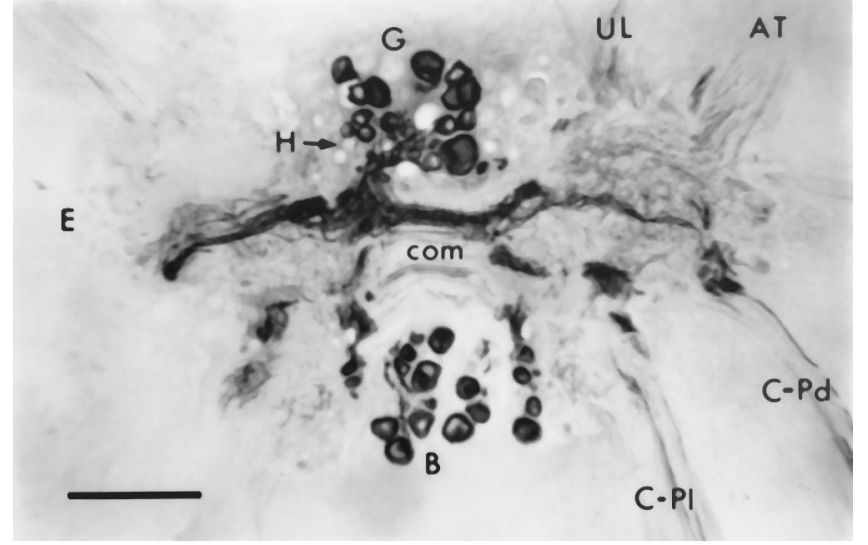

Figure 2. Section through the cerebral ganglia near ventral surface showing CP2-lir in the cytoplasm of neuronal cell bodies in the regions of the $B, G$, and $H$ clusters visualized using GAR-biotin and ABC-HRP. Large immunoreactive fibers extend from these clusters and extend across the commissure (com) and leave the ganglion in the cerebral-pedal $(C-P d)$ and cerebral-pleural $(C-P l)$ connectives. Smaller fibers with varicosities are found throughout the neuropil. $A T$, Anterior tentacular nerve; $E, \mathrm{E}$ cluster; $U L$, upper lip nerve. Photomicrograph is viewed from the ventral side, so right and left ganglia appear reversed. Scale bar, $200 \mu \mathrm{m}$.

glion contained immunoreactive fibers and because very few neurons in this ganglion contained CP1-lir and CP2-lir, we investigated whether some of the $\mathrm{CP} 1$ and $\mathrm{CP} 2$ in these tissues might be synthesized in the cerebral ganglia and transported to the abdominal ganglion and then out peripheral nerves. To test for this, cerebral ganglia were incubated in $\left[{ }^{35} \mathrm{~S}\right]$ methionine, and the relative amounts of labeled $\mathrm{CP} 1$ and $\mathrm{CP} 2$ transported to the pleuralabdominal connectives, abdominal ganglion, and peripheral nerves leaving the abdominal ganglion were determined. Although most of the radiolabeled CP1 and CP2 was associated with the connectives and the abdominal ganglion $(76.4 \pm 6.3 \%$ total transported $\mathrm{CP} 1$ and $60.1 \pm 7.9 \%$ total transported CP2; mean \pm SEM; $n=7$ ), labeled CP1 and CP2 were also detected in the peripheral nerves. Most of the labeled CP1 and CP2 were found in the branchial nerve $(15.3 \pm 3.7 \%$ of $\mathrm{CP} 1$ and $26.0 \pm 5.2 \%$ of $\mathrm{CP} 2$ ). Occasionally, labeled $\mathrm{CP} 1$ or $\mathrm{CP} 2$ was also detected in the siphon or genital nerve, although the level of this transport varied between experiments. Labeled CP1 or CP2 was not recovered from the pericardial nerve, an observation consistent with the lack of immunoreactivity in the heart and kidney, two of the major tissues innervated by this nerve (Kandel, 1979).

\section{Synthesis of CP1 and CP2 by single neurons}

We analyzed peptide synthesis in individual neurons as an independent method for determining whether CP1 and CP2 were colocalized in neuronal cell bodies. Intracellular recordings were made from neurons in the $\mathrm{B}, \mathrm{G}$, and $\mathrm{H}$ clusters of the cerebral ganglia to characterize their spontaneous activity, action potential durations, and in some cases, their synaptic connections. The neurons were then stained with fast green injected via the intracellular electrode and incubated with $\left[{ }^{35} \mathrm{~S}\right]$ methionine. Individual cell bodies were then dissected and extracted, and labeled peptides were analyzed by HPLC using HFBA as the counterion. Examples of HPLC of extracts from individual neurons from each of the clusters are shown in Figure 6, and the content of radiolabeled peptide corrected for the number of methionine residues in each peptide is summarized in Figure 8. For the neurons listed below, the labeled CP1 and CP2 peaks from the first HPLC runs 

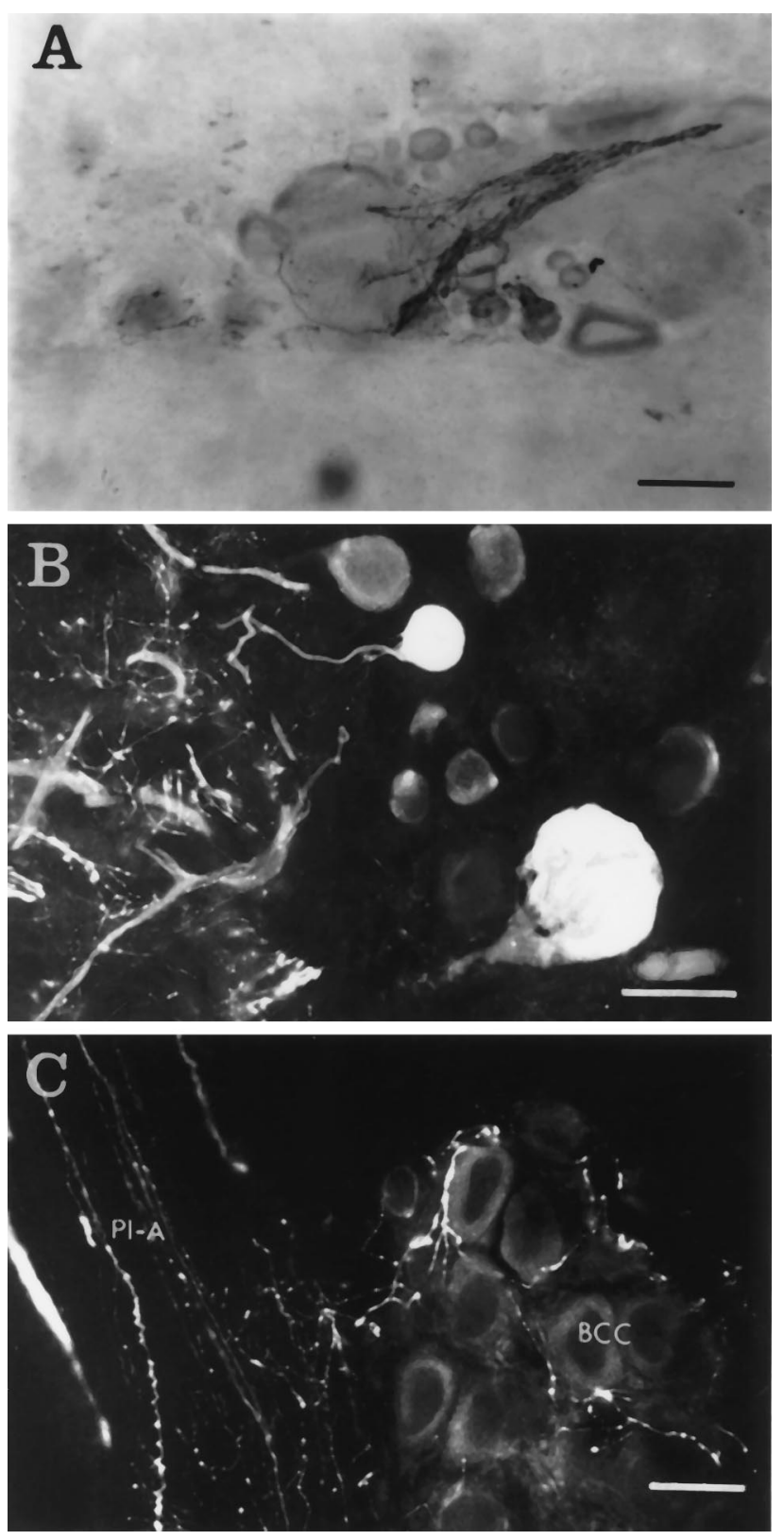

Figure 3. $\mathrm{CP} 2$-lir in the other ganglia. $A$, Immunoreactive fibers and varicosities surrounding the axon hillock and cell body of a neuron in the buccal ganglia visualized using GAR-biotin and ABC-HRP. Scale bar, $100 \mu \mathrm{m}$. $B$, Two immunoreactive neurons in the right caudal quadrant of the abdominal ganglion visualized using GAR-FITC. These neurons are part of a cluster of $\sim 10$ immunoreactive neurons scattered between identified neurons R2 and R15. The neuropil to the left of the cell bodies contains immunoreactive smooth and varicose fibers. Scale bar, $50 \mu \mathrm{m}$. $C$, Immunoreactive varicose fibers in the bag cell cluster $(B C C)$ and the pleural-abdominal connective $(P l-A)$ visualized using GAR-FITC. Scale bar, $50 \mu \mathrm{m}$.

continued to coelute with their respective synthetic peptides when aliquots of the peaks were analyzed by a second HPLC gradient using a different counterion (TFA).

\section{B cluster neurons}

Neurons in the B clusters of the cerebral ganglia can be divided into two major subpopulations on the basis of location, morphology, the nature of their synaptic connections, and biophysical characteristics (Teyke et al., 1989). Bn neurons have narrow (rapid) action potentials, receive input from A neurons and other Bn neurons, and are located predominantly on the dorsal sides of the ganglia, whereas $\mathrm{Bb}$ neurons have broad action potentials, do not receive input from either A neurons or other B neurons, and are located predominantly on the medial ventral region of the ganglia (Fig. 5). On the basis of the location of immunoreactive cell bodies, we predicted that $\mathrm{Bb}$ neurons would synthesize CP1 and $\mathrm{CP} 2$, whereas Bn neurons would not. Indeed, all Bb neurons that were analyzed ( 9 of 9 ) and no Bn neurons ( 0 of 4 ) synthesized $\mathrm{CP} 1$ and $\mathrm{CP} 2$. Action potential durations at half-maximal amplitude were $8.2 \pm 0.9$ msec (mean $\pm \mathrm{SEM} ; n=9$ ) for Bb neurons and $2.8 \pm 0.7 \mathrm{msec}(n=4)$ for Bn neurons. When the levels of synthesis for the two peptides in Bb neurons were compared, it was found that these neurons produced about half as much CP1 as they did CP2 (Fig. 8). We also determined that all Bn neurons that were analyzed (4 of 4 ) synthesized another neuropeptide, FMRFamide (Fig. 7); thus, the division of the $\mathrm{B}$ cluster neurons into $\mathrm{Bb}$ and $\mathrm{Bn}$ populations is also supported by the nature of their neuropeptide expression.

\section{G cluster neurons}

Many of the $G$ cluster neurons that were analyzed (9 of 19) synthesized both CP1 and CP2 (Fig. 6). These neurons were found in the medial region of the cluster, predominantly on the ventral surface (Fig. 5). Like the $\mathrm{Bb}$ neurons, these $\mathrm{G}$ cluster neurons synthesized about half as much CP1 as CP2 (Fig. 8). These neurons were either silent or spontaneously active at low rates $(\leq 1 \mathrm{~Hz})$ in the isolated cerebral ganglia, and they had broad action potentials (duration at half amplitude $=9.8 \pm 1.5 \mathrm{msec}$; $n=9$ ). The neurons that did not synthesize CP1 or CP2 usually were located more laterally in the cluster, did not seem to synthesize significant amounts of any methionine-containing peptides, and had narrower action potentials $(4.0 \pm 0.2 \mathrm{msec} ; n=10)$.

\section{H cluster neurons}

We have shown previously that pooled $\mathrm{H}$ cluster neurons synthesized CP1 and an unidentified peptide using a gradient that would not elute CP2 (Phares and Lloyd, 1996). In the present study, we found that all $\mathrm{H}$ cluster neurons that were analyzed (10 of 10) synthesized CP1 and CP2 as well as small amounts of the unidentified peptide (Fig. 6). It seems likely that all of the neurons in this cluster synthesize at least the three peptides. In contrast to $\mathrm{Bb}$ and $\mathrm{G}$ cluster neurons that synthesized $\mathrm{CP} 1$ and $\mathrm{CP} 2, \mathrm{H}$ cluster neurons synthesized more CP1 than CP2 (Fig. 8). Immunocytological evidence suggested that $\mathrm{H}$ cluster neurons also contained BuA (Miller et al., 1992), which contains a methionine residue and thus should be detected by our labeling procedure. Although the unidentified peptide elutes very close to synthetic BuA on the first gradient (counterion: HFBA), no labeled BuA was detected on a second gradient using a different counterion (TFA; $n=4$ ).

\section{Other neurons}

Some N cluster neurons (2 of 6 ) did synthesize low levels of CP1 and $\mathrm{CP} 2$ (Fig. 6). The finding that some neurons in the $\mathrm{N}$ cluster did not seem to synthesize CP1 and CP2 was unexpected, because all neurons in this cluster were positive for CP1-lir and CP2-lir. Our inability to detect synthesis of $\mathrm{CP} 1$ or $\mathrm{CP} 2$ in some of the $\mathrm{N}$-cluster neurons could be attributable to their small sizes. Many of these neurons had small diameters and were flattened rather than spherical, thereby further reducing their volume. It is also possible that N-cluster neurons synthesized the peptides at lower specific rates than neurons from the other cerebral clusters that were analyzed. 

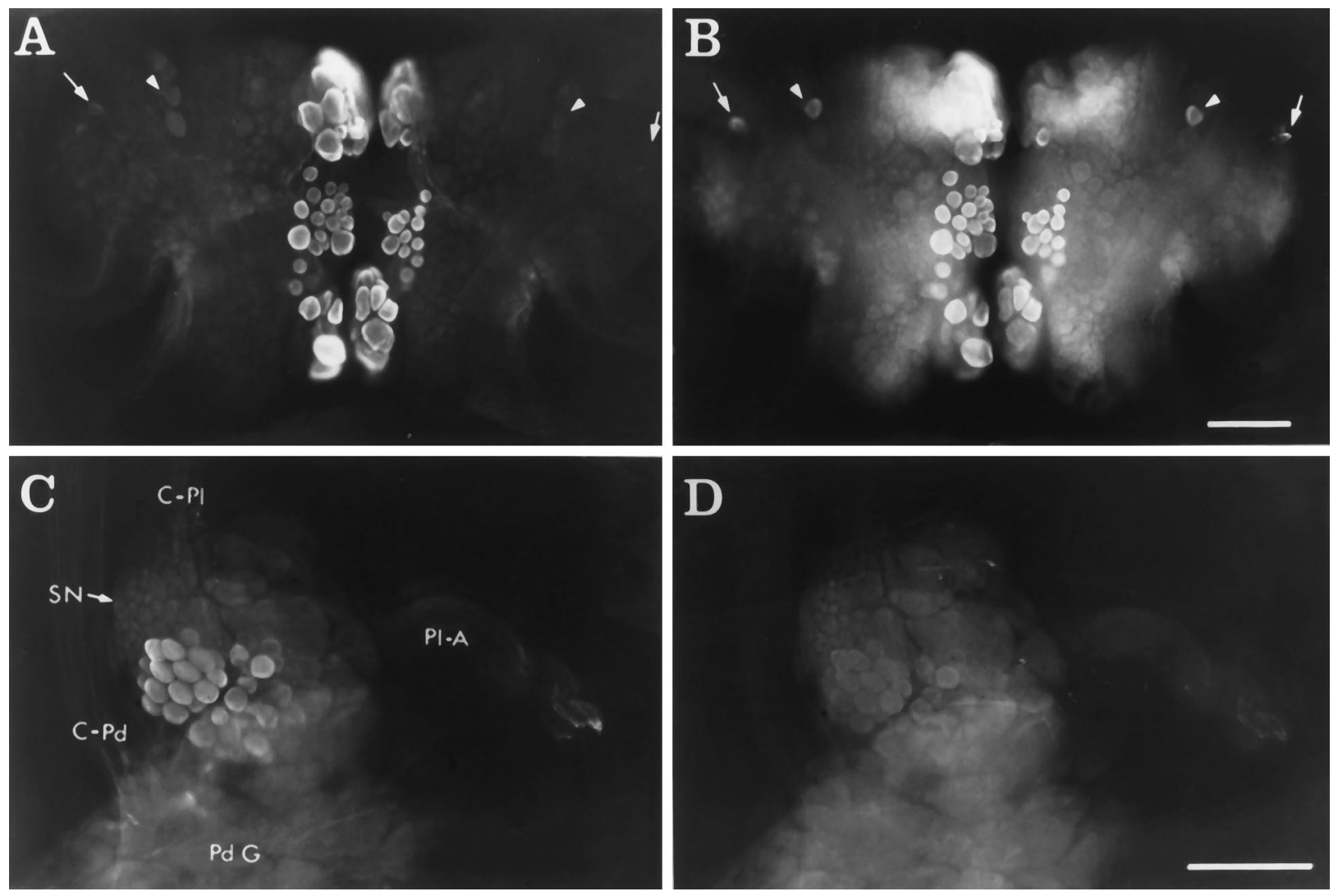

Figure 4. $\mathrm{CP} 1$-lir and CP2-lir in whole mounts. $A$, Ventral surface of the cerebral ganglia showing CP2-lir using GAR(IgG)-AMCA as the secondary antiserum. $B$, Same view as in $A$ showing CP1-lir using GAR(Fab)-FITC as the secondary antiserum. In $A$ and $B$, arrowheads indicate bilaterally symmetrical neurons in the $\mathrm{M}$ clusters, and arrows indicate bilaterally symmetrical neurons in rostral E clusters that contain CP1-lir but no detectable $\mathrm{CP} 2$-lir. $C$, Medial surface of right pleural ganglion showing CP2-lir using GAR(Fab)-LR as the secondary antiserum. $D$, Same view as in $C$, showing CP1-lir using GAR(IgG)-FITC as the secondary antiserum. Medial pleural neurons contain CP2-lir but no detectable CP1-lir. Other immunoreactive neurons in the anterior region of the ganglion are out of the plane of focus (see Fig. 5). $C$ - $P d$, Cerebral-pedal connective; $C$ - $P l$, cerebral-pleural connective; $P d G$, pedal ganglion; $P l-A$, pleural-abdominal connective; $S N$, sensory neuron cluster. Scale bar, $200 \mu \mathrm{m}$.

Although the $\mathrm{Bb}$, medial $\mathrm{G}$, and $\mathrm{H}$ neurons described above synthesized both $\mathrm{CP} 1$ and $\mathrm{CP} 2$, our immunocytological results indicated that other neurons synthesized only CP1 or CP2. These neurons are either isolated or very small, so our attempts to measure peptide synthesis in them have met with limited success. We did find, however, a single example of a neuron in the $\mathrm{M}$ cluster that seemed to synthesize only CP1 (data not shown), consistent with our observation that one neuron in each $\mathrm{M}$ cluster contained CP1-lir but no CP2-lir (Fig. 4). Also, neurons from the asymmetric cluster found in the right pleural ganglion synthesized CP2 but not CP1 (10 of 19 analyzed; Fig. 7). This agrees with results from immunocytology, which showed that neurons in this region contained only CP2-lir (Fig. 4). Of the 10 pleural neurons that synthesized CP2, six also synthesized FMRFamide, and four synthesized an unidentified methionine-containing peptide. Of the pleural neurons that did not synthesize $\mathrm{CP} 2$, all synthesized FMRFamide ( 9 of 9). These neurons were located posterior and dorsal to the $\mathrm{CP} 2$ cluster.

We wished to determine which of the cerebral clusters described above contained neurons that were likely to synthesize $\mathrm{CP} 1$ and $\mathrm{CP} 2$ and transport them to the abdominal ganglion. To do this, we identified neurons in clusters in the cerebral ganglia on the basis of location and electrophysiological properties that we had previously found to synthesize CP1 and CP2, and we stimulated the pleural-abdominal connective with a suction electrode to determine whether these neurons sent an axon into the connective. The pleural-abdominal connective is the major neural connection between head ganglia, including the cerebral ganglia and the abdominal ganglion. Antidromic spikes were observed in most of the Bb neurons (15 of 26), many of the medial $\mathrm{G}$ neurons (6 of 15), and none of the $\mathrm{H}$ neurons ( 0 of 15$)$ tested. It seems most likely that transport of $\mathrm{CP} 1$ and $\mathrm{CP} 2$ is occurring in the axons of the $\mathrm{Bb}$ and $\mathrm{G}$ neurons, although the possibility of blockade of antidromic spike conduction at axon branches of $\mathrm{H}$ neurons cannot be excluded.

\section{Electrophysiological responses of neurons in the buccal and abdominal ganglia to CP2}

Neuronal cell bodies that were densely innervated with varicosities containing CP2-lir were particularly prominent in the buccal and abdominal ganglia (Fig. $3 A$ ). Thus, it seemed most likely that neurons in these ganglia would respond to $\mathrm{CP} 2$ applied via the bath. As reported previously, we have not yet found any biological activity for CP1 on central neurons (Phares and Lloyd, 1996); however, a number of identified neurons in the buccal and abdominal ganglia were depolarized by the application of synthetic $\mathrm{CP} 2$. Specifically, we tested the effects of CP2 on neurons that could be identified by a combination of size, location, appearance, the nature of their spontaneous activity, and synaptic connections with other identified neurons. 


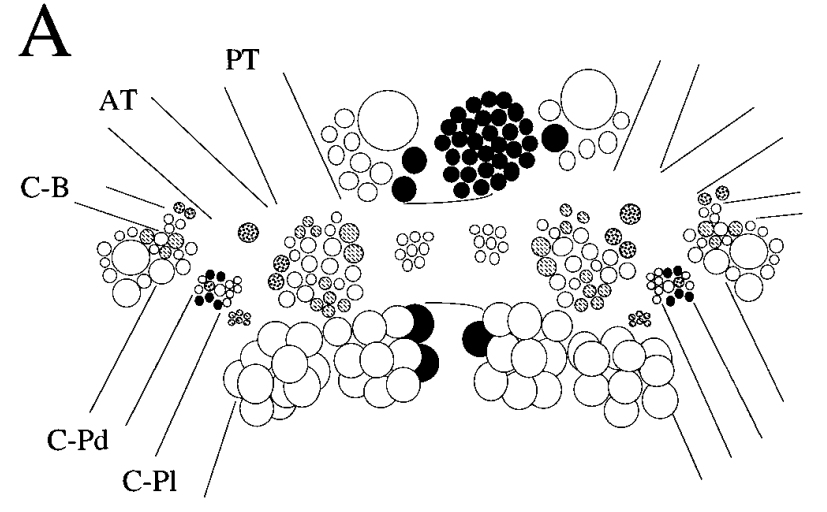

B

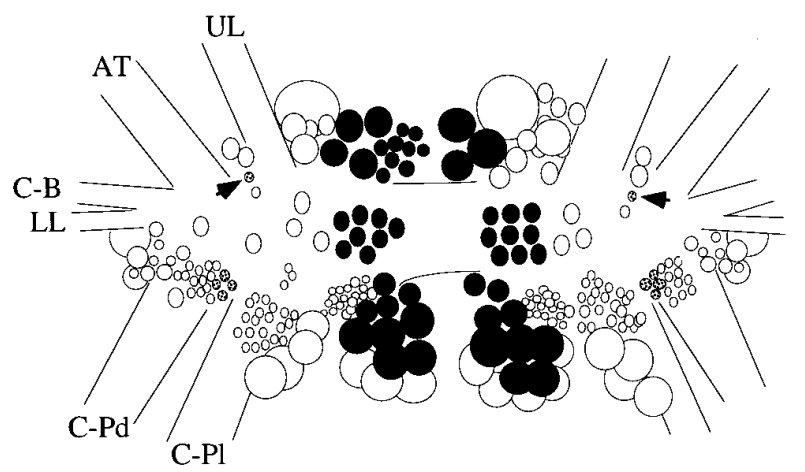

$\mathcal{C}$

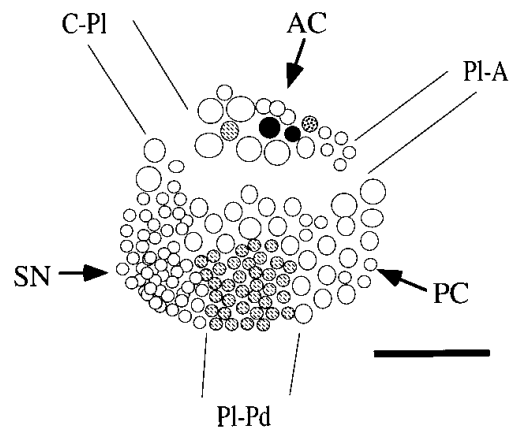

CP1

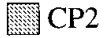

$\mathrm{CP} 1+\mathrm{CP} 2$

Figure 5. Schematic diagrams of the location of neuronal cell bodies containing CP1-lir or CP2-lir, or both CP1-lir and CP2-lir in selected ganglia. $A$, Dorsal surface of the cerebral ganglia. $B$, Ventral surface of the cerebral ganglia. Arrows indicate the positions of isolated individual neurons in the M clusters that contained CP1-lir only. $C$, Medial surface of the right pleural ganglion. Nerves from the cerebral ganglia are designated as in Fredman and Jahan-Parwar (1976). $A C$, Anterior cluster; $A T$, anterior tentacular nerve; $C$ - $B$, cerebral-buccal connective; $C$ - $P d$, cerebral-pedal connective; $C$ - $P l$, cerebral-pleural connective; $L L$, lower lip nerve; $P C$, posterior cluster; $\mathrm{Pl}-\mathrm{A}$, pleural-abdominal connective; $\mathrm{Pl}-\mathrm{Pd}$, pleuralpedal connective; $P T$, posterior tentacular nerve; $S N$, sensory neuron cluster; $U L$, upper lip nerve. Scale bar, $200 \mu \mathrm{m}$ (applies to $A-C$ ).

\section{Buccal ganglia}

The buccal ganglia contain many of the neurons that mediate consummatory feeding behaviors, i.e., biting, swallowing, and rejection (Kupfermann, 1974). In nASW, bolus applications of CP2 to the isolated buccal ganglia elicited buccal motor program (BMP)-like rhythmic activity in many of the identified motor neurons in the ventral cluster (Fig. 9A). These effects did not

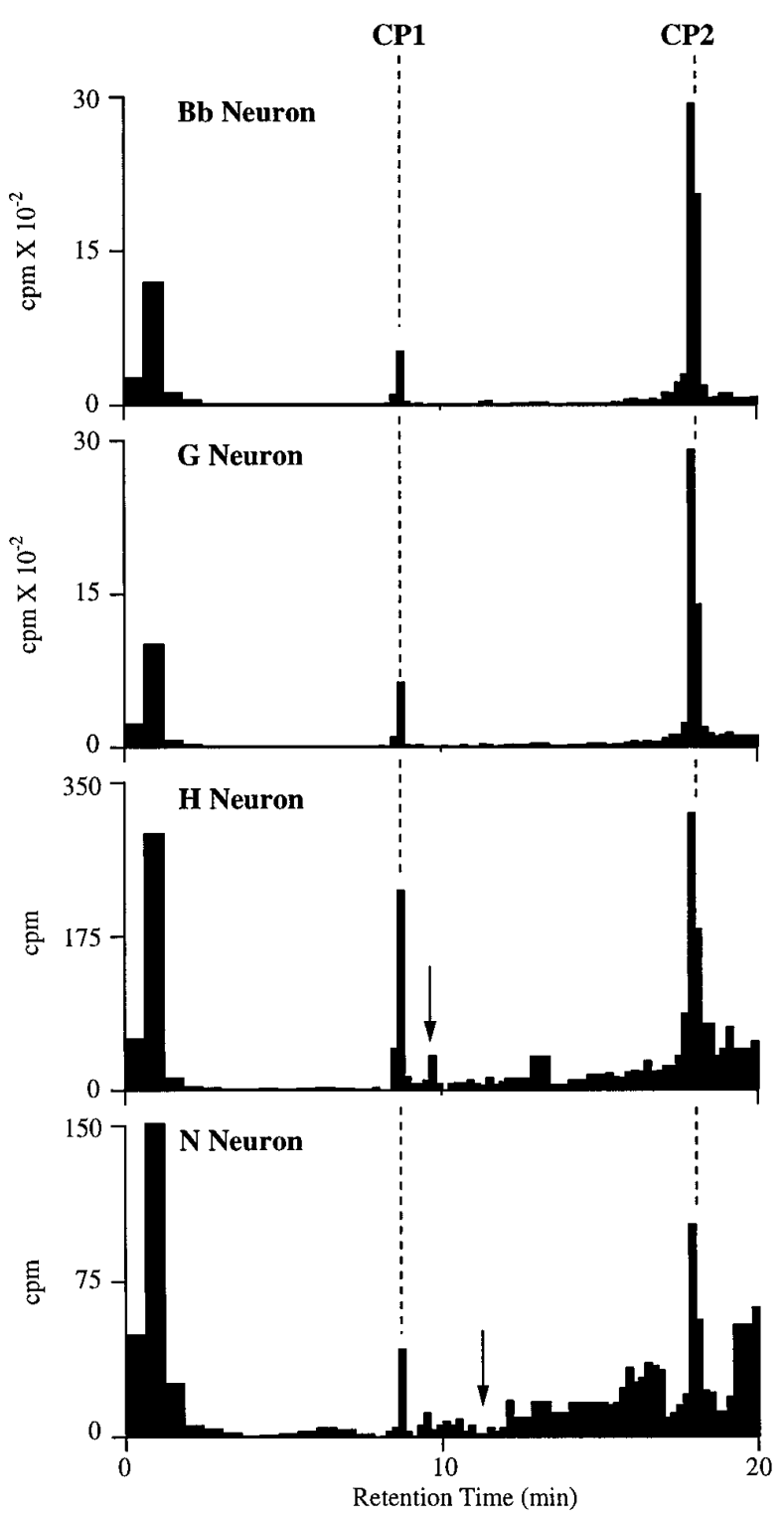

Figure 6. Examples of HPLC of extracts from individual neurons dissected from clusters in the cerebral ganglia that were positive for CP1-lir and CP2-lir. Cell extracts were run with HFBA as the counterion. Dashed lines indicate the retention times of synthetic CP1 and CP2 as monitored by absorbance. For each neuron, the identities of CP1 and CP2 were confirmed by running aliquots from these peaks on HPLC with TFA as a counterion. Arrows represent the retention times for synthetic BuA in the $\mathrm{H}$ neuron profile and synthetic $\mathrm{MmA}$ in the $\mathrm{N}$ neuron profile (see text). Aliquots of the peak that seems to coelute with $\mathrm{BuA}$ in the $\mathrm{H}$ neuron profile on this gradient did not coelute with BuA when run with TFA as a counterion. In this and the next figure, unincorporated $\left[{ }^{35} \mathrm{~S}\right]$ methionine is the predominant component of the broad peak, with brief retention time $(0-3 \mathrm{~min})$ that in some cases is truncated (i.e., $N$ Neuron $)$.

persist in low Ca ASW, which inhibits chemical synaptic transmission, suggesting that they were not direct effects on these neurons. The relative timing of bursts in these neurons is useful in identifying the nature of the BMPs (Cropper et al., 1990; Morton and Chiel, 1993; Church and Lloyd, 1994). Two basic BMPs have been described: ingestive BMPs (iBMPs) and egestive BMPs (eBMPs). In the patterned activity application of $\mathrm{CP} 2$ that was caused, B4 and $\mathrm{B} 7$ fired in phase with each other, a characteristic of eBMPs (Fig. 9A). Bursts in B4 and B5 were weaker than in either type of 


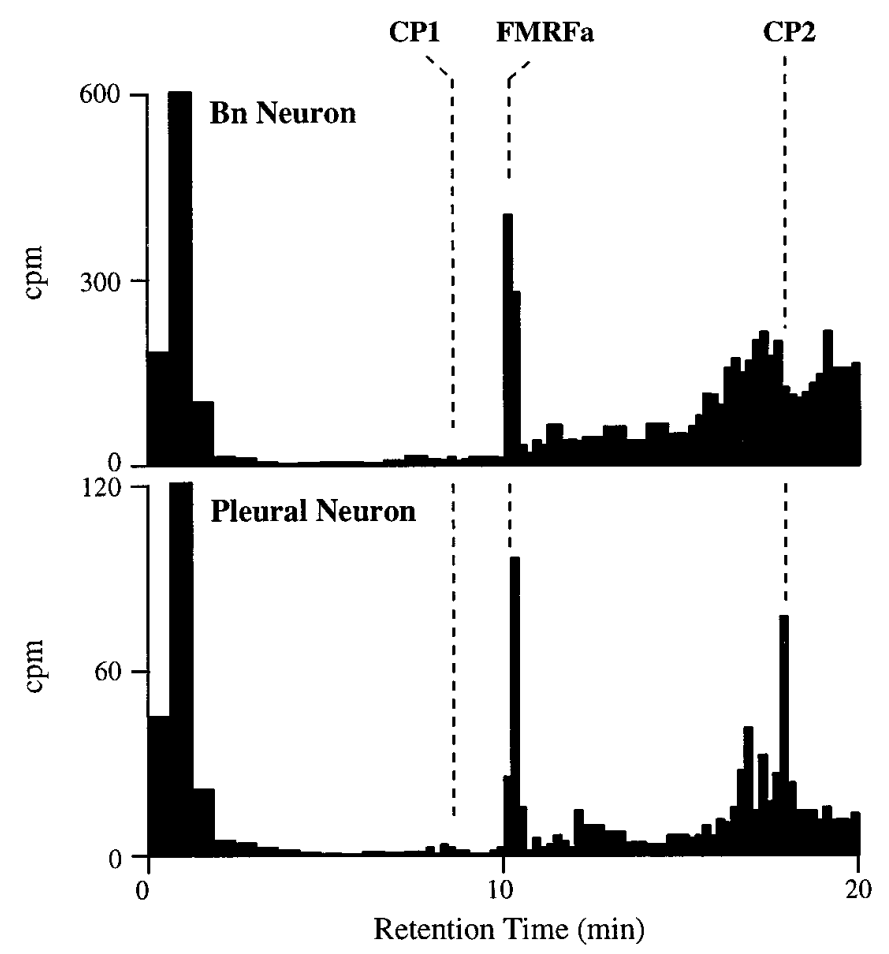

Figure 7. Examples of HPLC of extracts from individual neurons dissected from the cerebral Bn cluster, which was not immunoreactive for $\mathrm{CP} 1$ or $\mathrm{CP} 2$, and the asymmetric right pleural ganglion cluster, which was positive for CP2-lir but not CP1. Cell extracts were run with HFBA as a counterion, as in Figure 6. Dashed lines indicate the retention times of synthetic $C P 1$, FMRFamide $(F M R F a)$, and $C P 2$ as monitored by absorbance. The identities of FMRFamide and $\mathrm{CP} 2$ were confirmed by running aliquots from these peaks on HPLC with TFA as a counterion.

BMP; however, the pattern observed in B38 was more similar to that observed during a weak iBMP. Also, application of CP2 caused bursts of action potentials in neurons such as B1, B2, and B13, which do fire during iBMPs but not during eBMPs. Thus, application of CP2 evoked patterned activity that had some characteristics of an iBMP, the pattern being similar but not identical to iBMPs evoked by stimulation of cerebral-to-buccal interneuron 2 (Rosen et al., 1991; Church and Lloyd, 1994). Of the many neurons recorded from in the buccal ganglia, we found only one identified neuron that seemed to respond directly to $\mathrm{CP} 2$. This neuron, termed B41 (Ono, 1989), depolarized in response to CP2, and this effect persisted in low Ca ASW (Fig. 9B). Intracellular stimulation of B41 produced synaptic potentials in many other neurons but did not elicit a BMP; thus CP2 must also act on other premotor neurons in the buccal ganglia to initiate the BMP.

\section{Abdominal ganglion}

In nASW, many neurons in the isolated abdominal ganglion did respond to the application of $\mathrm{CP} 2$ with a change in their ongoing activity. When $\mathrm{CP} 2$ was applied in low $\mathrm{Ca} \mathrm{ASW}$, however, the responses were no longer present, suggesting that they were indirect. In RB cells recorded in $\mathrm{nASW}, \mathrm{CP} 2$ elicited a series of hyperpolarizing responses that seemed to be attributable to bursts of action potentials in an inhibitory neuron presynaptic to the RB neurons. This input seemed similar to that produced by R20 neurons, which are a pair of very similar electrically coupled neurons that modulate respiratory pumping (Alevizos et al., 1989). Accordingly, we recorded from R20 neurons and found that $\mathrm{CP} 2$ produced a dose-dependent depolarization (11 of 11

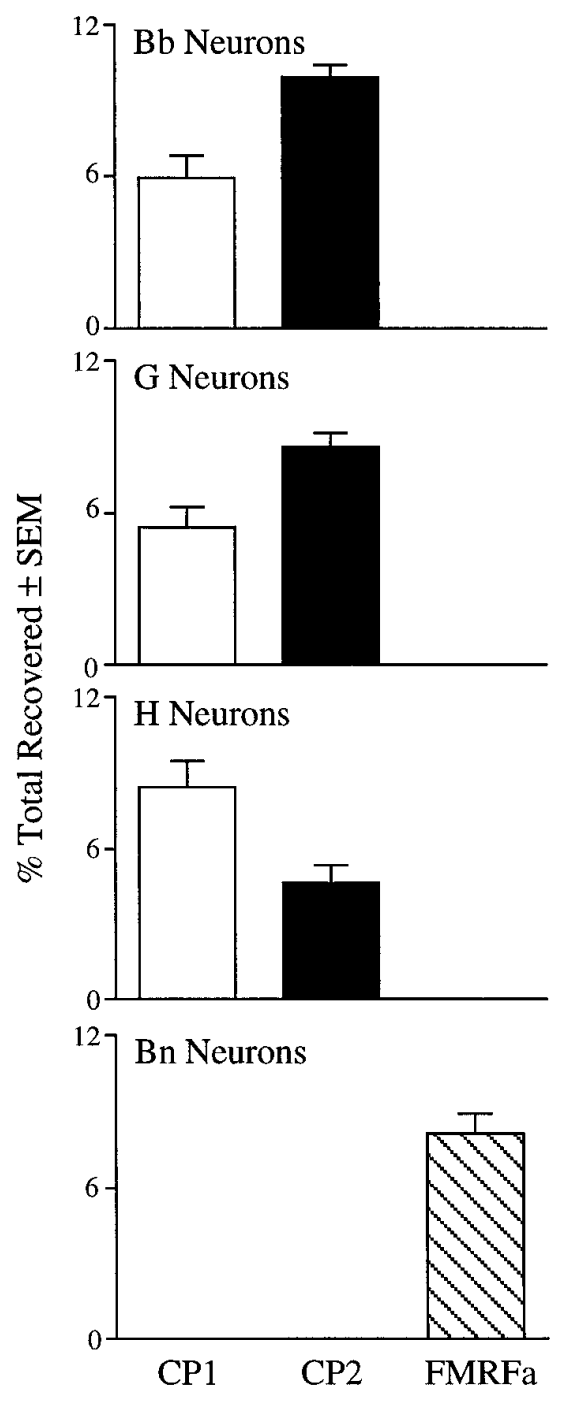

Figure 8. Radiolabeled peptide content in neurons from selected clusters of the cerebral ganglia. Incorporation into peptides is represented as the percentage of total radioactivity recovered from HPLC runs to compensate for the wide range of sizes of the neuronal cell bodies. In addition, the radioactivity associated with $\mathrm{CP} 2$ was divided by 3 , because this peptide contains three methionine residues, whereas CP1 and FMRFamide each contain one methionine residue. Values are mean \pm SEM, with $n=9$ for $\mathrm{Bb}, 9$ for $\mathrm{G}, 10$ for $\mathrm{H}$, and 4 for Bn neurons.

neurons analyzed). In nASW, the depolarization was often accompanied by a volley of IPSPs (Fig. 10). In low Ca ASW, CP2 continued to evoke a depolarization of similar amplitude and time course, suggesting that it was a direct action on R20 neurons, whereas the compound IPSP was no longer observed, suggesting that it was an indirect effect of $\mathrm{CP} 2$ on other neurons presynaptic to the R20 neurons. Similar responses, including the direct depolarization and indirect recruitment of a compound PSP, were observed in other neurons in the abdominal ganglion, some of which were in the respiratory pumping circuit, including the R25 (3 of 3), RG (15 of 15), LD (3 of 3), and L7 (5 of 5) neurons (Frazier et al., 1967; Koester and Kandel, 1977; Alevizos et al., 1989; Koester, 1989). In multifunction neuron L7, the indirect input evoked by $\mathrm{CP} 2$ was an excitatory-inhibitory PSP that was coincident with the IPSP recorded in other neurons. Other neurons that are in the respiratory pumping circuit, such as R15 (4 of 4) and L11 (4 of 4), seemed to receive only the indirect compound 
A
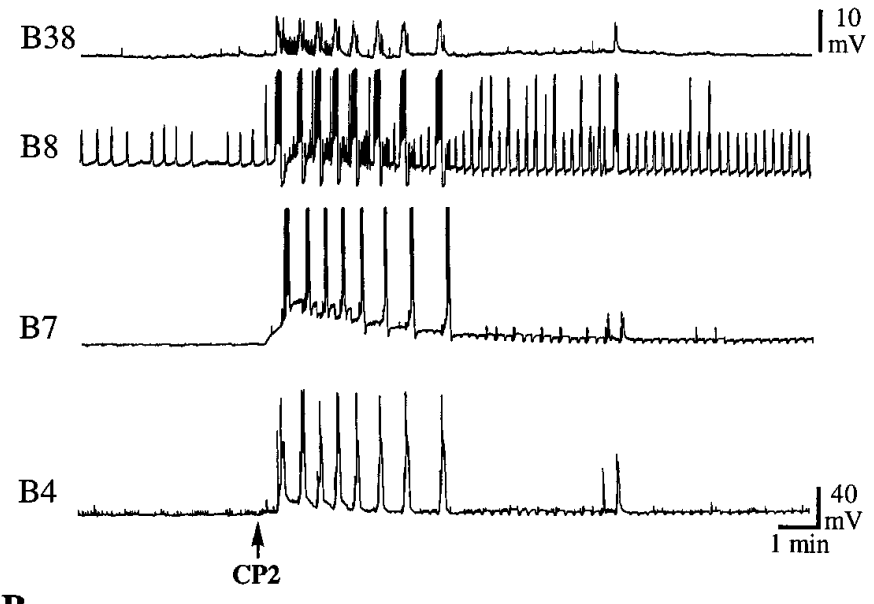

B

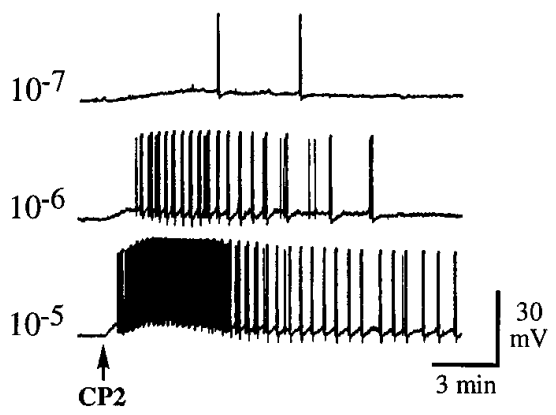

Figure 9. Responses of neurons in the buccal ganglia to bolus applications of CP2. $A$, Bolus application of $10^{-5} \mathrm{M}$ CP2 in nASW evokes rhythmic inputs into three ventral cluster motor neurons $(B 38, B 8$, and $B 7)$ and multifunctional neuron B4. $B$, Depolarization of B41 by bolus applications of $\mathrm{CP} 2$ at the indicated concentrations. B41 was identified by relative size and position and its synaptic connections to B4 and B13 (Ono, 1989). This experiment was performed in low Ca ASW to suppress chemical synaptic transmission. Similar results were obtained from B41 neurons in other preparations ( 7 of 7 analyzed).

IPSP and did not respond directly to CP2. In addition, neuron L5 seemed to be depolarized directly by CP2 (4 of 4), but it did not receive any indirect input. Thus, CP2 elicited various responses when applied in nASW but either no response or a depolarization when applied in low Ca ASW.

\section{Injection of CP2 into intact animals}

We were interested in determining the behavioral effects of injected CP2. First, we tested whether CP2 was stable in Aplysia hemolymph, which rapidly degrades a number of neuropeptides (Hall and Lloyd, 1990; Squire et al., 1991; Rothman et al., 1992). Combined radiolabeled and synthetic $\mathrm{CP} 2$ (total concentration $\sim 1 \mu \mathrm{M}$ ) were incubated with either freshly collected hemolymph or previously boiled hemolymph as a control, and aliquots were analyzed by HPLC. CP2 was stable in boiled hemolymph. It was also quite stable in fresh hemolymph: only $2.5 \%$ was broken down after a $10 \mathrm{~min}$ incubation and $5.2 \%$ after $20 \mathrm{~min}$, suggesting that injected CP2 might remain active for some time.

CP2 was injected into the hemocoel of four freely behaving animals in quantities that would reach a final concentration of $\sim 3$ $\mu \mathrm{M}$ if distributed evenly in the animal. This concentration was chosen because it reliably elicited responses in neurons in isolated ganglia (see above). Control animals were injected with nASW only. Four consistent changes in behavior were observed in the
A

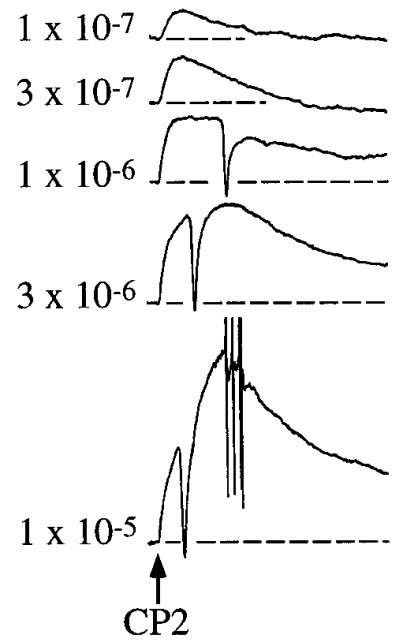

B

Figure 10. Responses of neurons in the abdominal ganglion to bolus applications of CP2. $A$, Depolarization of R20 by bolus application of CP2 at the indicated concentrations. R20 was identified by relative size and position, pigmentation, pronounced spike broadening exhibited during repetitive firing, synaptic connections to $\mathrm{RB}$ or $\mathrm{RG}$ neurons, and the nature of its responses to applications of FMRFamide and myomodulin (Alevizos et al., 1989). This experiment was performed in nASW. Note that, in addition to a dose-dependent depolarization of R20, the higher doses of $\mathrm{CP} 2$ also recruited a large hyperpolarizing response that was made up of a number of individual IPSPs when observed at a faster time base. $B$, Depolarization of R20 by bolus application of CP2 at the indicated concentrations. This experiment was performed in low $\mathrm{Ca}$ ASW to suppress chemical synaptic transmission. CP2 continued to cause a dosedependent depolarization similar in amplitude and time course to those observed in $A$, but no compound IPSPs were recruited. Records in $A$ and $B$ are from the same neuron. Similar results were obtained from R20 neurons in other preparations (11 of 11 analyzed).

animals injected with $\mathrm{CP} 2$. Consistent with the results from the electrophysiological studies, there was a marked increase in the rate of respiratory pumping. No RPs were observed in control animals before or after injection; however, animals given CP2 showed a marked increase in the frequency of RPs that peaked 15-20 min after the injection (Fig. 11). This is similar to the time course for the initiation of egg-laying behavior in animals injected with synthetic egg-laying hormone (Bernheim and Mayeri, 1995). The earliest observable effects of CP2 were an increase in rapid locomotion, a loss in the ability of the medial and posterior regions of the foot to attach to the substrate, and uncoordinated contractions of the parapodia. Consummatory feeding behaviors such as biting were not observed in any of the animals injected with $\mathrm{CP} 2$, although it is possible that other ingestive behaviors (e.g., swallowing) or small movements of the buccal mass occurred but were not visible.

\section{DISCUSSION}

CP2-lir was found in approximately 200 neurons located predominantly in the cerebral ganglia. Less numerous, smaller immunoreactive neurons were also found in the abdominal, pleural, and buccal ganglia, but none were observed in the pedal ganglia. The results from immunoblots and labeling experiments suggestd that at least most of this immunoreactivity represents authentic CP2. Results from immunocytological and biochemical procedures indicate that CP2 is colocalized with $\mathrm{CP} 1$ in neurons of the $\mathrm{Bb}$ cluster, the medial ventral $\mathrm{G}$ cluster, and the $\mathrm{H}$ cluster in the 


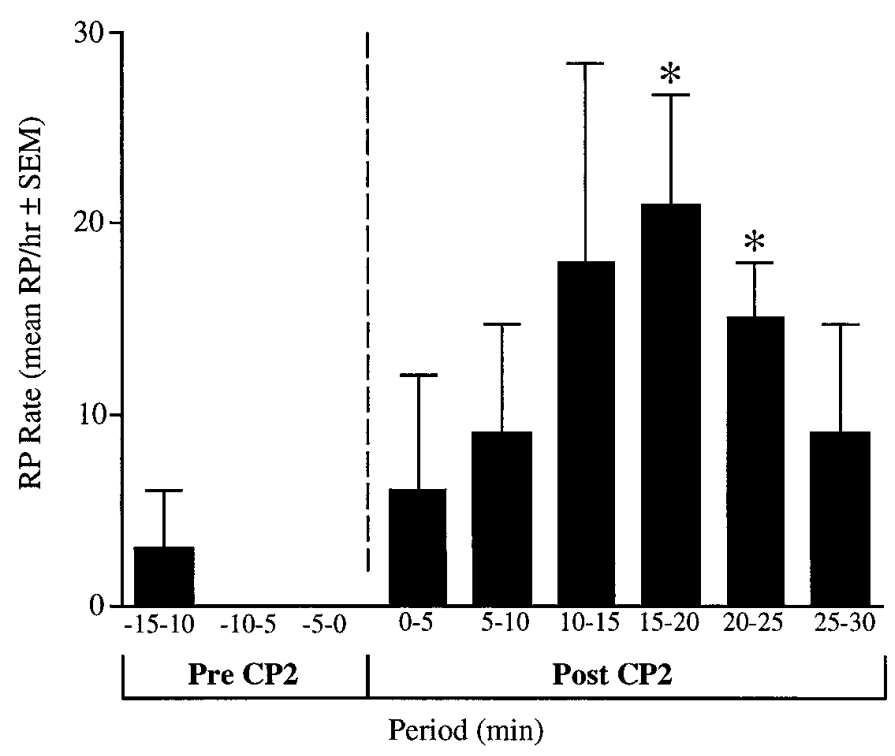

Figure 11. RP rates were increased by injections of synthetic CP2 into freely behaving animals. Animals (four pairs) were observed for $15 \mathrm{~min}$, injected with either nASW (control) or nASW containing CP2, and observed for an additional $30 \mathrm{~min}$. No RPs were observed in the control animals before or after injections. The figure shows the mean RP rate $(\mathrm{RP} / \mathrm{hr})$ in $5 \mathrm{~min}$ periods before and after the CP2 injections. (* indicates significant differences from the control group, using $t$ test and 0.05 significance levels.)

cerebral ganglia; however, the colocalization of $\mathrm{CP} 1$ and $\mathrm{CP} 2$ is a complex phenomenon. The relative content of radiolabeled CP1 and CP2 varies between neurons from different clusters, and some neurons contain only $\mathrm{CP} 1$ or $\mathrm{CP} 2$ but not both. It is possible that a single mRNA or precursor protein for $\mathrm{CP} 1$ and $\mathrm{CP} 2$ is processed differently in different neurons or that the expression of separate genes gives rise to precursor proteins for $\mathrm{CP} 1$ or $\mathrm{CP} 2$. Currently, we have no way to distinguish between these possibilities. We also observed the coexpression of $\mathrm{CP} 2$ and FMRFamide in an asymmetric cluster of small neurons in the right pleural ganglion. This cluster was not described in previous studies of the distribution of FMRFamide-like immunoreactivity in the pleural ganglia (Soinila and Mpitsos, 1991; Small et al., 1992). In addition to the overlap with CP1-lir in the cerebral ganglion, the location of neurons that contained CP2-lir was distinct from that reported for other peptides in Aplysia, with two exceptions: neurons in the cerebral $\mathrm{H}$ cluster contain buccalin-like immunoreactivity (Miller et al., 1992), and neurons in the newly designated cerebral $\mathrm{N}$ cluster contain myomodulin-like immunoreactivity (Miller et al., 1991). We found no evidence, however, for buccalin synthesis in the entire H cluster (Phares and Lloyd, 1996) or in this study in individual $\mathrm{H}$ cluster neurons. It is unlikely that the antiserum directed against buccalin is binding to $\mathrm{CP} 1$ and $\mathrm{CP} 2$, because there is little sequence similarity among the peptides, and other neurons that contain CP1-lir and CP2-lir do not contain buccalinlike immunoreactivity. It is possible that the buccalin antiserum binds to the unidentified methionine-containing peptide we found to be synthesized in $\mathrm{H}$ cluster neurons. The low levels of synthesis in $\mathrm{N}$ cluster neurons made it difficult to determine whether they might synthesize myomodulin in addition to CP1 and CP2.

$\mathrm{CP} 1$ and $\mathrm{CP} 2$ were identified originally because they were the major methionine-labeled peptides transported from the cerebral ganglia to the abdominal ganglion. Our results suggest that neurons from the $\mathrm{Bb}$ and medial $\mathrm{G}$ clusters are the most likely candidates for the neurons that synthesize CP1 and CP2 and transport them along axons from the cerebral ganglia to the abdominal ganglion. These results agree with those of a more general study in which antidromic responses were recorded from neurons in a number of clusters in the cerebral ganglia while stimulating the pleural-abdominal connective (Jahan-Parwar and Fredman, 1976). Neurons in these clusters are also labeled by backfills of the pleural-abdominal connective (Fredman, 1987; Ferguson et al., 1989) or retrograde-labeling from the abdominal ganglion with fluorescent dyes (Hawkins, 1989; McPherson and Blankenship, 1991). Bb neurons are putative modulatory neurons that send axons into both the cerebral-pedal and the cerebralpleural connectives and out various peripheral nerves of the pleural and pedal ganglia to innervate the body wall and foot (Teyke et al., 1989). They may also innervate the body wall in the mantle region via the peripheral nerves of the abdominal ganglion. $\mathrm{Bn}$ and $\mathrm{Bb}$ neurons were differentiated originally on the basis of physiological and morphological characteristics (Teyke et al., 1989). They now can also be differentiated on the basis of their expression of neuropeptides: all $\mathrm{Bb}$ neurons that were analyzed synthesized $\mathrm{CP} 1$ and $\mathrm{CP} 2$, whereas all $\mathrm{Bn}$ neurons synthesized FMRFamide. Neurons containing FMRFamide-like immunoreactivity have been localized to the region of the B cluster occupied predominantly by Bn neurons (Soinila and Mpitsos, 1991). Also, it is likely that some $\mathrm{Bn}$ neurons send axons into the pleuralabdominal connective (Jahan-Parwar and Fredman, 1976; Mackey et al., 1989). Thus, Bn neurons may account for some of the FMRFamide found to be transported from the cerebral ganglion to the abdominal ganglia and perhaps to the pedal and pleural ganglia as well (Lloyd, 1989).

In the $\mathrm{B}$ and $\mathrm{G}$ clusters, where $\mathrm{CP} 1$ - and $\mathrm{CP}$ 2-containing neurons were intermingled with neurons that do not express these peptides, we have attempted to make it possible for others studying neurons in these clusters to be able to determine whether a neuron expressed CP1 and CP2 from its electrophysiological properties alone. Fortunately, this turned out to be relatively straightforward, because bimodal distribution of action potential durations correlated accurately with the expression of CP1 and CP2. In both clusters, neurons with action potentials of relatively long duration expressed $\mathrm{CP} 1$ and $\mathrm{CP} 2$, and neurons with action potentials of relatively short duration did not. The long duration action potentials, however, were not simply correlated with peptide expression, because Bn neurons expressed FMRFamide at levels comparable to the expression of $\mathrm{CP} 1$ and $\mathrm{CP} 2$ in $\mathrm{Bb}$ neurons.

It has been suggested that the $\mathrm{H}$ cluster may be homologous to the the asymmetric region of the right mesocerebrum of the pulmonate snail, Helix pulmonata, and the anterior lobe of the right cerebral ganglion of Lymnaea stagnalis (Miller et al., 1991). Neurons in these regions seem to innervate the penis (Chase, 1986; Croll and van Minnen, 1992; Smit et al., 1992; Li and Chase, 1995); however, few H cluster neurons send axons into the pathways from the cerebral ganglia to the penis (Jahan-Parwar and Fredman, 1976). Results presented here suggest that H-cluster neurons do not represent a major input to the penis, because these neurons actually synthesize more CP1 than CP2, but only CP2-lir was observed in this tissue.

Electrophysiological results suggest that neurons that synthesize CP2 may be involved in the generation of behaviors in the buccal and abdominal ganglia. In the buccal ganglia, CP2 seemed to activate neurons that initiate patterned activity in ventral cluster motor neurons. It is possible that $\mathrm{CP} 2$-containing cerebral 
neurons may be the normal source of CP2 in the buccal ganglia. It has been shown that the presence of the cerebral ganglia is necessary for biting, an ingestive behavior (Kupfermann, 1974). Neurons containing CP2-lir are present in both the E and G clusters of the cerebral ganglia. Neurons in these clusters modulate buccal motor programs and feeding behaviors (Weiss et al., 1978; 1986; Chiel et al., 1986, 1988; Rosen et al., 1991), and several axons containing CP2-lir were observed in the cerebralbuccal connective.

In the abdominal ganglion, CP2 directly depolarized both R20 and R25 neurons, two neuronal groups that participate in the initiation or modulation of respiratory pumping (Alevizos et al., 1989; Koester, 1989). The cerebral ganglia do seem to play a role in the regulation respiratory pumping, because lesioning them reduces the increase in pumping rate produced by elevated $\mathrm{CO}_{2}$ levels (Levy and Susswein, 1993). Unfortunately, we have not yet identified neurons in the cerebral ganglia that synthesize CP2 and are presynaptic to the R20 or R25 neurons.

Freely behaving animals injected with CP2 increased their respiratory pumping rate consistent with the effects of the peptide on identified neurons in the abdominal ganglion. Because CP2 was stable in hemolymph and is similar in size to several known neurohormones in Aplysia (Chui et al., 1979; Campanelli and Scheller, 1987; Weiss et al., 1989; Nagle et al., 1990), it may also act as a neurohormone. Injected CP2 may also act on neurons in the cerebral and pedal ganglia that initiate or mediate locomotion or parapodial movements.

We have identified a new peptidergic transmitter that seems to be used by a large number of neurons in the cerebral ganglia and has potent excitatory effects on many neurons in other ganglia in Aplysia. These results suggest that using fast axonal transport of labeled peptides as an assay for identifying transmitter-like peptides is a powerful procedure that may have wide application to other neural systems in Aplysia and other animals.

\section{REFERENCES}

Alevizos A, Weiss KR, Koester J (1989) SCP-containing R20 neurons modulate respiratory pumping in Aplysia. J Neurosci 9:3058-3071.

Bernheim SM, Mayeri E (1995) Complex behavior induced by egg-laying hormone in Aplysia. J Comp Physiol [A] 176:131-136.

Campanelli JT, Scheller RH (1987) Histidine-rich basic peptide: a cardioactive neuropeptide from Aplysia neurons R3-14. J Neurophysiol 57:1201-1209.

Chase R (1986) Brain cells that command sexual behavior in the snail Helix aspersa. J Neurobiol 17:669-679.

Chiel HJ, Weiss KR, Kupfermann I (1986) An identified histaminergic neuron modulates feeding motor circuitry in Aplysia. J Neurosci 6:2427-2450.

Chiel HJ, Weiss KR, Kupfermann I (1988) An identified histaminergic neuron can modulate the outputs of buccal-cerebral interneurons in Aplysia via presynaptic inhibition. J Neurosci 8:49-63.

Chui AY, Hunkapiller MW, Heller E, Stuart DK, Hood LE, Strumwasser F (1979) Purification and primary structure of the neuropeptide egglaying hormone of Aplysia californica. Proc Natl Acad Sci USA 76:6656-6660.

Church PJ, Lloyd PE (1991) Expression of diverse neuropeptide cotransmitters by identified motor neurons in Aplysia. J Neurosci 11:618-625.

Church PJ, Lloyd PE (1994) Activity of multiple identified motor neurons recorded intracellularly during evoked feedinglike motor programs in Aplysia. J Neurophysiol 72:1794-1809.

Croll RP, van Minnen J (1992) Distribution of the peptide Ala-Pro-GlyTrp- $\mathrm{NH}_{2}$ (APGWamide) in the nervous system and periphery of the snail Lymnaea stagnalis as revealed by immunocytochemistry and in situ hybridization. J Comp Neurol 324:567-574.

Cropper EC, Kupfermann I, Weiss KR (1990) Differential firing patterns of the peptide-containing cholinergic motor neurons B15 and B16 during feeding behavior in Aplysia. Brain Res 522:176-179.
Ferguson GP, ter Maat A, Pinsker HM (1989) Egg laying in Aplysia. II. Organization of central and peripheral pathways for initiating neurosecretory activity. J Comp Physiol [A] 164:849-857.

Frazier WT, Kandel ER, Kupfermann I, Waziri R, Coggeshall RE (1967) Morphological and functional properties of identified neurons in the abdominal ganglion of Aplysia californica. J Neurophysiol 30:1288-1351.

Fredman SM (1987) Intracellular staining of neurons with nickel-lysine. J Neurosci Methods 20:181-194.

Hall JD, Lloyd PE (1990) Involvement of pedal peptide in locomotion in Aplysia: modulation of foot muscle contractions. $\mathrm{J}$ Neurobiol 21:858-868.

Hawkins RD (1989) Localization of potential serotonergic facilitator neurons in Aplysia by glyoxylic acid histofluorescence combined with retrograde fluorescent labeling. J Neurosci 9:4214-4226.

Jahan-Parwar B, Fredman SM (1976) Cerebral ganglion of Aplysia: cellular organization and origin of nerves. Comp Biochem Physiol 54A:347-357.

Kandel ER (1979) Behavioral biology of Aplysia. San Francisco: W. H. Freeman.

Kehoe J (1972) Three acetylcholine receptors in Aplysia neurones. J Physiol (Lond) 225:115-146.

Koester J (1989) Chemically and electrically coupled interneurons mediate respiratory pumping in Aplysia. J Neurophysiol 62:1113-1126.

Koester J, Kandel ER (1977) Further identification of neurons in the abdominal ganglion of Aplysia using behavioral criteria. Brain Res 121:1-20.

Kupfermann I (1974) Feeding behavior in Aplysia: a simple system for the study of motivation. Behav Biol 10:1-26.

Levy M, Susswein AJ (1993) Separate neural pathways respond to different noxious stimuli affecting respiratory pump frequency in Aplysia fasciata. Brain Res 616:218-229.

Li G, Chase R (1995) Correlation of axon projection and peptide immunoreactivity in mesocerebral neurons of the snail Helix aspersa. J Comp Neurol 353:9-17.

Lloyd PE (1989) Interganglionic axonal transport of neuropeptides in Aplysia. J Neurosci 9:3243-3249.

Longley RD, Longley AJ (1986) Serotonin immunoreactivity of neurons in the gastropod Aplysia californica. J Neurobiol 17:339-358.

Mackey SL, Kandel ER, Hawkins RD (1989) Identified serotonergic neurons LCB1 and RCB1 in the cerebral ganglia of Aplysia produce presynaptic facilitation of siphon sensory neurons. J Neurosci 9:4227-4235.

McPherson DR, Blankenship JE (1991) Retrograde labelling of serotonergic projections onto the neuroendocrine bag cells of Aplysia. Neurosci Lett 123:148-151.

Miller MW, Alevizos A, Cropper EC, Vilim FS, Karagogeos D, Kupfermann I, Weiss KR (1991) Localization of myomodulin-like immunoreactivity in the central nervous system and peripheral tissues of Aplysia californica. J Comp Neurol 314:627-644.

Miller MW, Alevizos A, Cropper EC, Kupfermann I, Weiss KR (1992) Distribution of buccalin-like immunoreactivity in the central nervous system and peripheral tissues of Aplysia californica. J Comp Neurol 320:182-195.

Morton DW, Chiel HJ (1993) The timing of activity in motor neurons that produce radula movements distinguishes ingestion from rejection in Aplysia. J Comp Physiol [A] 173:519-536.

Nagle GT, de Jong-Brink M, Painter SD, Bergamin-Sassen MM, Blankenship JE, Kurosky A (1990) Delta-bag cell peptide from the egglaying hormone precursor of Aplysia: processing, primary structure, and biological activity. J Biol Chem 265:22329-22335.

Ono JK (1989) Synaptic connections in the buccal ganglia of Aplysia mediated by an identified neuron containing a CCK/gastrin-like peptide co-localized with acetylcholine. Brain Res 493:212-224.

Ono JK, McCaman RE (1980) Identification of additional histaminergic neurons in Aplysia: improvement of single cell isolation techniques for in tandem physiological and chemical studies. Neuroscience 5:835-840.

Pearson WL, Lloyd PE (1989) Immunocytological localization of pedal peptide in the central nervous system and periphery of Aplysia. J Neurosci 9:318-325.

Phares GA, Lloyd PE (1996) Purification, primary structure, and neuronal localization of cerebral peptide 1 from Aplysia. Peptides 17:753-761. Phares GA, Walent JH, Niece RL, Kumar SB, Ericsson LH, Kowalak JA, Lloyd PE (1996) Primary structure of a new neuropeptide, cerebral 
peptide 2, purified from cerebral ganglia of Aplysia. Biochemistry 35:5921-5927.

Rosen SC, Teyke T, Miller MW, Weiss KR, Kupfermann I (1991) Identification and characterization of cerebral-to-buccal interneurons implicated in the control of motor programs associated with feeding in Aplysia. J Neurosci 11:3630-3655.

Rothman BS, Dekruyff S, Talebian M, Menon JG, Squire CR, Che-Hung Y, Lee TD (1992) Aplysia peptide neurotransmitters $\beta$-bag cell peptide, Phe-Met-Arg-Phe-amide, and small cardioexcitatory peptide $\mathrm{B}$ are rapidly degraded by a leucine aminopeptidase-like activity in hemolymph. J Biol Chem 267:25135-25140.

Small SA, Cohen TE, Kandel ER, Hawkins RD (1992) Identified FMRFamide-immunoreactive neuron LPL16 in the left pleural ganglion of Aplysia produces presynaptic inhibition of siphon sensory neurons. J Neurosci 12:1616-1627.

Smit AB, Jimenez C, Dirks RW, Croll RP, Geraerts WPM (1992) Characterization of a cDNA clone encoding multiple copies of APGWamide, a neuropeptide involved in the control of male copulatory behavior in the mollusc, Lymnaea stagnalis. J Neurosci 12:1709-1715.

Soinila S, Mpitsos GJ (1991) Immunohistochemistry of diverging and converging neurotransmitter systems in molluscks. Biol Bull $181: 484-499$
Squire CR, Talebian M, Menon JG, Dekruyff SD, Lee TD, Shively JE, Rothman BS (1991) Aplysia peptide neurotransmitters $\beta$-bag cell peptide, Phe-Met-Arg-Phe-amide, and small cardioexcitatory peptide B are rapidly degraded by a leucine aminopeptidase-like activity in hemolymph. J Biol Chem 266:22355-22363.

Teyke T, Weiss KR, Kupfermann I (1989) A subpopulation of cerebral B cluster neurones of Aplysia californica is involved in defensive head withdrawal but not appetitive head movements. J Exp Biol 147:1-20.

Weiss KR, Cohen JL, Kupfermann I (1978) Modulatory control of buccal musculature by a serotonergic neuron (metacerebral cell) in Aplysia. J Neurophysiol 41:181-203.

Weiss KR, Chiel HJ, Koch U, Kupfermann I (1986) Activity of an identified histaminergic neuron, and its possible role in arousal of feeding behavior in semi-intact Aplysia. J Neurosci 6:2403-2415.

Weiss KR, Bayley H, Lloyd PE, Tenenbaum R, Gawinowicz-Kolks MA, Buck L, Cropper EC, Rosen SC, Kupfermann I (1989) Purification and sequencing of neuropeptides contained in neuron R15 of Aplysia californica. Proc Natl Acad Sci USA 86:2913-2917.

Wessel GM, McClay DR (1986) Two embryonic, tissue specific molecules identified by a double-label immunofluorescence technique for monoclonal antibodies. J Histochem Cytochem 34:703-706. 